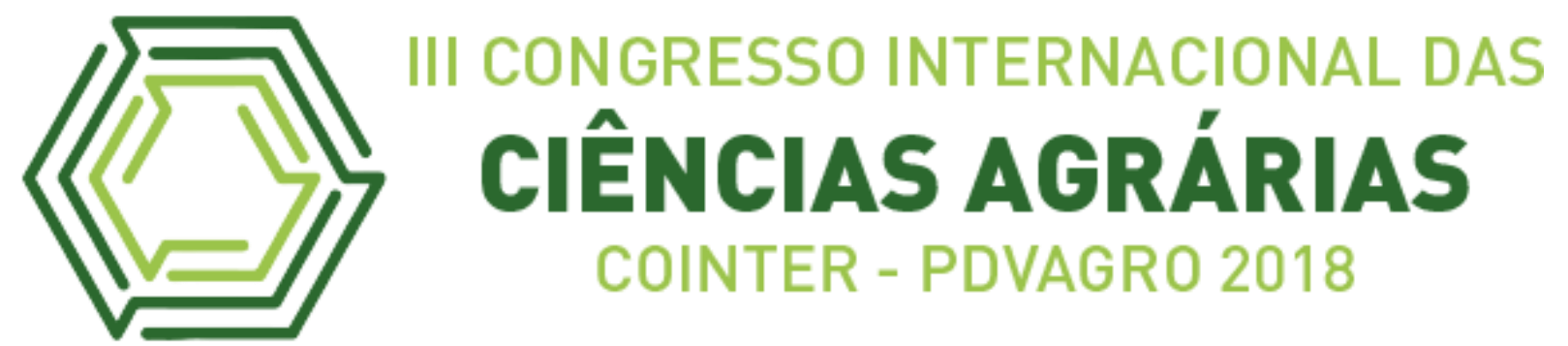

\title{
DETERMINAÇÃO DO TEOR DE UMIDADE EM MÉIS DE ABELHA COMERCIAIS DA CIDADE DE JOÃO PESSOA
}

\section{DETERMINATION OF THE HUMIDITY CONTENT IN COMMON BEES OF THE CITY OF JOÃO PESSOA}

\author{
Apresentação: Pôster \\ DOI: https://doi.org/10.31692/2526-7701.IIICOINTERPDVAGRO.2018.00425
}

\section{Introdução}

A Refratometria é um método físico em que se analisa o índice de refração de uma solução em concentração líquida. Sua definição é clara, e é conhecida como a mudança de direção de um feixe de luz ao trocar sua incidência de passagem do meio ambiente para a solução, com resultado final medido em ângulo de refração cuja medida é em graus (CECCHI, 2003; CORINGA, 2010; CALDAS et al., 2015).

Nesse sentido, o princípio da refratometria, baseia-se na lei de Snell-Descartes, onde o desvio angular suportado pelo raio de luz é refratado, ou seja, a penetração de luz no liquido, onde o raio de luz monocromática passa de uma região para outra é deformado considerando as características do liquido. A determinação da refração é dada pelo ângulo em graus e transformada em índice de refração. O índice da refração se sujeita a diferentes situações, sendo necessário o ajuste para condições, como a natureza química da substância, comprimento de onda de luz, temperatura, e concentração da solução. Os valores do índice de refração são medidos e comparados com um valor padrão previamente conhecido e cuja unidade de referência para os valores determinados é o grau Brix $\left({ }^{\circ} \mathrm{Bx}\right)$, que é a quantidade de sólidos solúveis em solução, ou seja, em alimentos corresponde a quantidade aproximada de açúcares, medida esta, que representa 1 grama de compostos solúveis totais a cada 100 gramas de solução (CECCHI, 2003; CORINGA, 2010).

Cecchi (2003) e Dornemann (2016), afirmam que a refratometria tem grande aplicação industrial, principalmente na indústria de alimentos, pois sempre é aplicada no controle de qualidade de alimentos, tendo como principal objetivo atingir padrões de qualidade que assegurem a satisfação dos consumidores. Estes mesmo autores, consideram que na análise de alimentos, a refratometria se torna importante, pois além de determinar o índice de refração de 
um alimento líquido de concentração conhecida, este visa determinar a qualidade destes produtos, de forma que, algumas determinações tornam-se imprescindíveis. Nesse sentido, a refratometria pode ser aplicada na determinação de pureza e qualidade de méis, xaropes de refrigerantes, sucos e polpas de frutas em gerais.

Portanto, este trabalho teve como objetivo determinar o teor de umidade em amostras de méis de abelha comerciais afim de averiguar a sua qualidade como produto comercial.

\section{Fundamentação Teórica}

O princípio da refratometria baseia-se na lei de Snell-Descartes, onde o desvio angular suportado pelo raio de luz é refratado, ou seja, a penetração de luz no liquido, onde o raio de luz monocromática passa de uma região para outra é deformado considerando as características do liquido. Os valores do índice de refração são medidos e comparados com um valor padrão previamente conhecido e cuja unidade de referência para os valores determinados é o grau Brix $\left({ }^{\circ} \mathrm{Bx}\right)$, que é a quantidade de sólidos solúveis em solução (CECCHI, 2003; CORINGA, 2010).

Mel é o produto natural elaborado por abelhas a partir de néctar de flores e/ou exsudatos sacarínicos de plantas. Deve ser designado por mel, ou simplesmente mel de abelha, e sua classificação varia de acordo com o processo de fabricação, ou seja, o mel virgem é produto que influi espontaneamente dos favos, quando desoperculados, e o mel industrial é aquele obtido por um processo industrial propriamente dito (BRASIL, 2000).

Ainda conforme Brasil (2000), O mel não poderá conter substâncias estranhas à sua composição normal, nem ser adicionado de corretivos de acidez e o máximo de umidade permitido no mel são de $20 \%$.

\section{Metodologia}

\section{Obtenção e preparo das amostras}

Para o objeto da pesquisa, foram obtidas três amostras de méis de abelha comerciais, adquiridas em supermercados da cidade de João Pessoa. Logo após a aquisição das amostras, os méis foram transportados em temperatura ambiente até ao laboratório de Engenharia de Alimentos, do Centro de Tecnologia, da Universidade Federal da Paraíba.

Para a determinação da porcentagem de água dos méis, as amostras foram codificadas em amostras A, B e C, e analisadas no mesmo dia de sua aquisição. 


\section{Calibração do refratômetro}

Antes da análise, foi feito a limpeza e calibração do refratômetro de bancada, da marca Abbé- BIOBRIX. O equipamento foi limpo com água destilada e depois cuidadosamente com papel absorvente. Em seguida calibrou-se o refratômetro de Abbe com água destilada, ajustando a parte clara e parte escura até a linha limite no plano de linhas cruzadas e escala do índice de refração para 1,33 que é o equivalente a $0^{\circ}$ Brix.

\section{Determinação da porcentagem de água dos méis}

As determinações da porcentagem de água nas amostras dos méis foi baseada pelo método refratométrico, que utiliza a conversão do índice de refração a $20{ }^{\circ} \mathrm{C}$ em porcentagem de umidade. E para esta determinação, adicionou-se uma gota de cada amostra de mel na lente do refratômetro e em seguida direcionou-se a luz para realização das medidas. A determinação foi feita em triplicata para cada amostra e seus resultados expressos em médias.

\section{Resultados e Discussões}

Os dados obtidos na determinação do teor de umidade nas amostras de mel de abelha estão dispostos na Tabela 1 .

Como pode ser visto na Tabela 1, A umidade (\%) foi calculada por interpolação utilizando o índice de refração corrigido na temperatura de $20{ }^{\circ} \mathrm{C}$. A correção do índice de refração foi feita levando em consideração a temperatura da amostra analisada, e foi adicionado o valor de 0,00023 ao índice de refração de cada grau de temperatura lido acima de $20^{\circ} \mathrm{C}$.

De acordo com o Regulamento técnico de identidade e qualidade do mel, o máximo de umidade permitido no mel é de 20\% (BRASIL, 2000). Com isso, pode se verificar que apenas a amostra A obteve o valor de umidade acima do permitido pela legislação, enquanto que as outras amostras estão em conformidade.

Este valor de alta umidade pode ser explicado pelo simples fato de que quando os teores de umidade dos méis estão altos, estes podem estar e/ou ter sofrido fermentação de microrganismos osmofílicos, e estes microrganismos, encontram-se geralmente distribuídos em toda área de extração do mel, e/ou nos corpos das abelhas (VENTURINI et al., 2008; GOIS, 2011; SILVA, 2013). 

Tabela 1- Determinação de porcentagem de água no mel

\begin{tabular}{cccccc}
\hline Amostras & T $\left({ }^{\circ} \mathbf{C}\right)$ & ${ }^{\circ} \mathbf{B r i x}$ & IR & $\begin{array}{c}\text { IR } \\
\mathbf{T}\left(\mathbf{2 0}^{\circ} \mathbf{C}\right)\end{array}$ & $\begin{array}{c}\text { Umidade } \\
(\boldsymbol{\%})\end{array}$ \\
\hline A & 30 & 67,5 & 1,4600 & 1,4830 & 21,4 \\
B & 28 & 72,5 & 1,4710 & 1,4894 & 18,8 \\
C & 28 & 73,1 & 1,4720 & 1,4904 & 18,4 \\
\hline
\end{tabular}

Marchini et al., (2004), afirmam que a água é o segundo componente em quantidade na composição do mel, e este parâmetro influi características importantes, visto que na composição do mel, a água pode influenciar no seu sabor, maturidade, peso específico, viscosidade e conservação.

Para Góis (2011), o conhecimento do teor de umidade em méis de abelha se tornar primordial e de grande importância na conservação e armazenamento deste produto, visto que, a umidade está inteiramente ligada na manutenção de sua qualidade e no seu processo de comercialização. Por isso, é de em suma importância que os teores de umidade dos méis estejam dentro dos limites estabelecidos pela legislação brasileira.

\section{Conclusões}

A quantidade de água em produtos alimentícios está intrinsicamente ligada ao seu processo de conservação e na sua qualidade final. No mel, a água assume papel importante em sua composição química, e a determinação do seu teor pode influenciar no seu tempo de vida útil. Portanto, pode-se concluir que os objetivos pretendidos neste trabalho foi alcançado, demonstrando a importância de se determinar o teor de umidade em mel na verificação da sua qualidade como produto comercial. 


\section{Referências}

BRASIL. Ministério da Agricultura, Pecuária e Abastecimento. Instrução Normativa no 11, de 20 de outubro de 2000. Aprova o Regulamento Técnico de Identidade e Qualidade do Mel. Diário Oficial da União, de 23 de outubro de 2000, Seção 1, p. 23, 2000.

CALDAS, B. S. et al. Determinação de açúcares em suco concentrado e néctar de uva: comparativo empregando refratometria, espectrofotometria e cromatografia líquida. ScientiaChromatographica, v. 7, n. 1, p. 53-63, 2015.

CECCHI, H. M. Métodos físicos. In: Fundamentos teóricos e práticos em análise de alimentos. $2^{\text {a }}$ ed. UNICAMP: Campinas, 2003, p. 98-115.

IAL. Métodos físico-químicos para análise de alimentos. Instituto Adolfo Lutz. São Paulo. $2^{\circ}$ ed. digital. 2008.

CORINGA, E. A. O. Apostila de Análise Instrumental Aplicada a alimentos. Apostila. Cuiabá: IFMT. 2010.

DORNEMANN, G. M. Comparação de Métodos para Determinação de Açucares Redutores e Não-redutores. Rio Grande do Sul: UFRS, 2016. Disponível em: <https://www.lume.ufrgs.br/bitstream/handle/10183/143940/000998082.pdf?sequence=1 >.

Acesso em: 16 abr. 2018.

GOIS, G. C. CARACTERIZAÇÃO FÍSICO-QUÍMICA E QUALIDADE MICROBIOLÓGICA DO MEL DE Apis mellifera COMERCIALIZADOS NO ESTADO DA PARAIBA. 2011. 102 f. Dissertação (Mestrado) - Curso de Zootecnia, Universidade Federal da Paraíba, Areia, 2011. Disponível em: <http://www.cca.ufpb.br/ppgz/www/files/dissertacao2011/Caracterizao_Fsico-

Qumica_E_Qualidade_Microbiolgica_Do_Mel_De_Apis_Mellifera_Comercializados_No_Es tado_Da_Paraiba_-_G.pdf>. Acesso em: 16 abr. 2018.

SILVA, C. V. CARACTERÍSTICAS FÍSICO-QUÍMICAS DE MEL DE CAPIXINGUI E SILVESTRE DA REGIÃO DE ORTIGUEIRA-PR. 2013. 31 f. TCC - Curso de Alimentos, UTFP, Londrina, 2013. Disponível em: <http://repositorio.roca.utfpr.edu.br/jspui/bitstream/1/1422/1/LD_COALM_2013_1_09.pdf>. Acesso em: 24 abr. 2018.

VENTURINI, K. S.; SARCINElli, M. F; SilVA, L. C. da. Características do mel. Disponível em: www.agais.com./b01107/_caracteristicas_mel.pdf. Acesso em: 16 abr. 2018. 